\title{
Tradutores e intérpretes de Língua Brasileira de Sinais: uma perspectiva histórica da profissão
}

\author{
Brazilian Sign Language translators and interpreters: a historical perspective \\ of the profession
}

\section{Traductores e intérpretes de Lengua Brasileño de Señas: una perspectiva histórica de la profesión}

Daiana San Martins Goulart

Doutoranda na Universidade Luterana do Brasil, Canoas, RS, Brasil

E-mail: daianasmgoulart@gmail.com ORCID: https://orcid.org/0000-0001-9855-2388

\section{lara Tatiana Bonin}

Professora doutora da Universidade Luterana do Brasil, Canoas, RS, Brasil

E-mail: itbonin@gmail.com ORCID: https://orcid.org/0000-0001-7156-8849

Recebido em 04 de outubro de 2019

Aprovado em 09 de agosto de 2021

Publicado em 31 de agosto de 2021

\section{RESUMO}

A profissão de tradutor e intérprete de Língua Brasileira de Sinais (Libras) emerge e consolida-se em condições históricas específicas, em especial, no contexto das lutas das comunidades surdas brasileiras voltadas ao reconhecimento cultural e linguístico. Inscrito no campo teórico dos Estudos Culturais, este estudo tem como objetivo discutir como se constituiu a profissão dos tradutores e intérpretes de Língua Brasileira de Sinais - Libras. Recorre-se a estudos sobre a Educação de Surdos, a instituição da língua de sinais e a mediação linguística para entender o contexto a partir do qual a profissionalização foi sendo configurada e respaldada. A metodologia envolveu revisão de estudos e de documentos que regulamentam essa profissão no país, exames de proficiência em tradução/interpretação na Língua Brasileira de Sinais/Língua Portuguesa - PROLIBRAS, realizados entre 2006 e 2015 e, ainda, editais de concursos públicos, produzidos entre 2013 e 2016, para o provimento de cargos em Instituições de Ensino Superior.

Palavras-chave: Língua Brasileira de Sinais; Tradutores e Intérpretes; Profissionalização.

\section{ABSTRACT}

The brazilian sign language professional career of the translator and interpreter of Brazilian Sign Language (Libras) emerges and consolidates under specific historical conditions, especially in the context of battling and struggling of Brazilian deaf communities in order to obtain their cultural and linguistic recognition. As part of the theoretical field of Cultural Studies, this study aims to discuss how the profession of translators and interpreters of Libras - Brazilian Sign Language - was constituted. To understand the context from which their professionalization was configured and supported, the Studies on Deaf Education, the institution of sign language and linguistic mediation were used. The methodology used 
included reviewing studies and official documents which regulate this profession in the country, proficiency exams in translation/interpretation of the Brazilian Sign Language/Portuguese (PROLIBRAS, conducted between 2006-2015) and at public service entrance examination notices, applied to occupy positions in Higher Education Institutions, between 2013-2016.

Keywords: Brazilian Sign Language; Translators and Interpreters; Professionalization.

\section{RESUMEN}

La profesión de traductor e intérprete de lengua brasileño de señas surge y consolidase en condiciones históricas específicas, especialmente en el contexto de las luchas de las comunidades sordas brasileñas centradas en el reconocimiento cultural y lingüístico. Registrado en el campo teórico de los Estudios Culturales, este estudio tiene por objetivo discutir cómo se constituyó la profesión de los traductores e intérpretes de Libras Lenguaje de Señas Brasileño. Se utilizaron estudios sobre la educación para sordos, la institución del lenguaje de señas y la mediación lingüística para comprender el contexto desde el cual se configuró y apoyó la profesionalización. La metodología incluyó la revisión de la literatura, el estudio de documentos que regulan esta profesión en el país, exámenes de competencia en traducción / interpretación en lenguaje de señas brasileño/lengua portuguesa (PROLIBRAS, realizado entre 2006 y 2015) así como anuncios de procesos selectivos para puestos públicos en Instituciones de Educación Superior, entre 2013 y 2016.

Palabras clave: Lengua de Señas Brasileño; Traductores e intérpretes; Profesionalización.

\section{Considerações iniciais}

A profissão de Tradutor e Intérprete de Língua Brasileira de Sinais (Libras) regulamentada pela Lei n. 12.319 de $1^{\circ}$ de setembro de $2010^{1}$ - vai adquirindo contornos a partir de um conjunto de circunstâncias históricas que envolvem, por exemplo, as lutas das comunidades surdas brasileiras voltadas ao reconhecimento cultural e linguístico e/ou as estratégias utilizadas pelos tradutores e intérpretes para ter reconhecido e valorizado o seu trabalho. Operam, como elementos conjunturais relevantes, as vertentes multiculturalistas e interculturais que passam a matizar as propostas educacionais brasileiras a partir de finais dos anos 1990 e, também, o impulso que assumem as políticas governamentais inclusivas neste país, nas últimas décadas. Assim, como defende Martín-Barbero, a noção de diversidade se consolida, na atualidade, por meio de uma institucionalidade que envolve a cultura, em um plano global, e que interpela organismos de cada Estado/nação para que sejam incorporadas políticas de atenção a diferenciados segmentos populacionais. Contudo, conforme o autor: 
http://dx.doi.org/10.5902/1984686X40378

As permanentes homenagens à diversidade cultural que encontramos hoje, não só por parte dos governos e das instituições públicas internacionais, mas também de organizações do âmbito empresarial das indústrias culturais, são inversamente proporcionais ao que acontece no plano das políticas protetoras e incentivadoras dessa diversidade. Pois tudo, ou quase tudo, reside em níveis de decisão a que nem os atores do plano local têm acesso, nem os verdadeiros mediadores do plano mundial (MARTíN-BARBERO, 2014, p. 16).

Mais do que propagar a mensagem de que "somos todos diferentes", este momento exige que se instituam políticas públicas para reverter condições estruturantes das desigualdades e pode ser propícia. Neste sentido, a regulamentação e institucionalização da presença do tradutor e intérprete de Libras como mediador em todas as situações em que se faça necessária a mediação linguística e cultural.

O trabalho dos tradutores e intérpretes de línguas de sinais vai se consolidando como profissão na medida em que os surdos conquistam espaços em instâncias sociais, culturais e educacionais nas quais a maioria é ouvinte. Um conjunto de direitos para pessoas surdas se estabelece e culmina na oficialização da Língua Brasileira de Sinais, através da Lei no 10.436, de 24 de abril de 2002. Três anos depois, o governo brasileiro publica o decreto 5.626, de 22 de dezembro de 2005, que dispõe sobre a formação necessária para atuar como tradutor e intérprete de Língua Brasileira de Sinais. Contudo, a profissão só é reconhecida e regulamentada em 2010, por meio da Lei no 12.319/10.

Algumas instituições, em especial aquelas dedicadas ao ensino, passam a contemplar a especificidade da presença surda por meio da garantia de mediação linguística e cultural, feita por tradutores e intérpretes de Libras e de políticas específicas. Intensificam-se, também, as reivindicações para que ocorram traduções e interpretações em eventos, em pronunciamentos de representantes públicos, em programas televisivos e educativos, em instituições de atendimento de saúde, em instâncias do judiciário e, ainda, em espaços públicos de reivindicação, de controle social e de exercício da cidadania. A expansão do campo de atuação profissional também potencializou pesquisas desenvolvidas em âmbito acadêmico e dedicadas ao tema, especialmente nas áreas da Tradução e Interpretação, da Educação e da Saúde. Também emerge um conjunto de normas que prescrevem condições de ingresso na profissão, bem como parâmetros para a formação daqueles que atuam nesta modalidade.

A profissão "Tradutor-intérprete de Língua de Sinais" foi inserida na Classificação Brasileira de Ocupações ${ }^{2}$ e descrita como atividade concernente à tradução e interpretação oral e/ou em línguas de sinais - de um idioma para outro - considerando tanto variáveis 
http://dx.doi.org/10.5902/1984686X40378

culturais, quanto aspectos terminológicos e estilísticos de cada língua. Podem atuar de modo simultâneo ou consecutivo ao realizar o ato tradutório, e podem ser chamados a traduzir/interpretar em distintos ambientes, com emprego de tecnologias que favorecem ou ampliam o alcance de seu trabalho (registro e transmissão por aparelhos conectados à internet, por exemplo).

Tomando como acontecimento relevante a regulamentação e expansão da profissão de Tradutor e Intérprete de Libras, no presente artigo, colocamos em discussão elementos históricos e atuais que constituem o campo de ação dos profissionais, pensando em especial nas políticas públicas para formação e em requisitos que têm pautado a seleção de tradutores e intérpretes de Libras/língua portuguesa em editais de Instituições de Ensino Superior publicados entre 2013 e 2016.

\section{Um olhar retrospectivo: do voluntariado à profissionalização}

Como afirmamos anteriormente, a emergência de um campo profissional para atuação de tradutores e intérpretes de línguas de sinais está diretamente relacionada aos processos históricos de educação de surdos e às lutas por acessibilidade dos coletivos e movimentos surdos. Em âmbito internacional, a realização, em 1878, em Paris, do I Congresso Internacional sobre a Instrução de Surdos foi um marco nos debates em torno de experiências de educação. Naquele congresso, polarizavam-se as posições - de um lado, os que defendiam a oralização como forma mais eficaz de comunicação, de outro, os que defendiam o uso de línguas de sinais na educação de surdos. O Congresso possibilitou algumas conquistas para os surdos, a exemplo do reconhecimento da capacidade destes para assinar documentos e da manutenção das línguas de sinais em instâncias educativas.

Contudo, no II Congresso Internacional, também realizado em Milão, em 1880, alterou-se o cenário, e as línguas de sinais foram proibidas como meio de instrução, o que, conforme alguns autores, abre uma lacuna de aproximadamente 100 anos nos processos educativos que se fortaleciam, com base no uso dessas línguas em distintos países. Respaldou-se o uso do método oralista para a Educação de Surdos, estabelecendo-se, desse modo, o uso compulsório das línguas orais de cada país para a comunicação com estes sujeitos, o que também impossibilitou que a ação tradutória nas línguas de sinais fosse reconhecida e se expandisse.

No Brasil, os registros sobre a educação para surdos iniciam-se em 1855, e o marco inaugural seria a vinda do francês surdo Eduard Huet para criar uma escola nos moldes 
http://dx.doi.org/10.5902/1984686X40378

das que se organizaram na França. O então Imperador Dom Pedro II, após avaliar a proposta de Huet, Ihe concede, em 1857, um espaço provisório para atuação e, dois anos depois, funda-se no Rio de Janeiro uma instituição responsável pela educação de surdos inicialmente nomeada Instituto Nacional de Surdos-Mudos (INSM) e posteriormente chamada de Instituto Nacional de Educação para Surdos (INES).

Por décadas o instituto funcionou em regime de internato e recebeu alunos surdos de vários estados do Brasil que, em período de férias, retornavam aos seus estados de origem. Leite (2005) explica que, ao regressarem para suas localidades, os alunos do INES utilizavam e, assim, propagavam a língua de sinais francesa aprendida no Instituto. Isso promoveu uma mescla entre sinais da língua francesa e diferentes formas de expressão utilizadas pelas famílias de surdos, originando a Língua Brasileira de Sinais.

Os documentos históricos - atas, relatórios, cadernos de registros - do INES foram examinados por Rocha (2013) e Laguna (2015) e seus estudos dão relevo a aspectos importantes da história da educação de surdos. Registra-se, nestes documentos, que na década de 1950 alguns professores do instituto (em especial da disciplina de Educação Física, com quem os alunos tinham maior proximidade) atuavam como intérpretes em cerimônias ou eventos específicos, nos quais, a intermediação da comunicação entre surdos e ouvintes era requisitada. Rocha (2008) exemplifica com uma ocorrência policial, em 1907, no estado do Rio de Janeiro, envolvendo uma pessoa surda, momento em que a presença de intérprete foi solicitada e, portanto, formalizou-se o evento de mediação linguística feita por um professor do INES.

Segundo Tuxi (2009), há uma carência de documentação relativa ao trabalho de interpretação de línguas orais e de línguas de sinais, em decorrência do desprestígio social desta ocupação. No caso dos intérpretes de línguas de sinais, a pesquisadora destaca que, como sua atuação ocorreu, por longo tempo, em instituições religiosas, isso também contribuiu para que o trabalho fosse largamente vinculado a um sentido de "missão". Observamos, na atualidade, que essa vinculação persiste associada, algumas vezes, às noções de vocação e de abnegação, e gera, ainda, expectativas de voluntariado.

Sobre esse aspecto, a tradução e a interpretação mantiveram-se, por longo tempo, no campo do voluntariado, e isso não ocorreu apenas no Brasil. Conforme Quadros (2004), os tradutores e intérpretes surgem como "acompanhantes" de pessoas surdas e esse trabalho era desempenhado, majoritariamente, por familiares de surdos ou pessoas próximas à 
http://dx.doi.org/10.5902/1984686X40378

família que dominavam a língua de sinais, mas que, em geral, não dispunham de nenhuma formação específica.

Na Suécia há, de acordo com a autora, registros de trabalhos de intérpretes em instituições religiosas no final do século XIX. Em 1938, o parlamento sueco criou cinco cargos de conselheiros para surdos e, como tal medida não atendeu à demanda da comunidade surda. Em 1947, instituiu mais vinte vagas para a função de intérprete. Posteriormente, em 1968, em consequência da reivindicação da Associação Nacional dos Surdos, o parlamento decidiu que todos os surdos teriam direito ao acompanhamento gratuito de intérpretes. Naquele mesmo ano, criou-se o primeiro curso para intérpretes, organizado pela Associação Nacional de Surdos, a Comissão Nacional de Educação e a Comissão Nacional de Mercado de Trabalho naquele país.

Já nos Estados Unidos, a atuação de Thomas Gallaudet, iniciada em 1815, inaugura os registros sobre a atuação de um intérprete que acompanhava o surdo francês Laurent Clerc, importante nome da Educação de Surdos. Sherman Wilcox e Phyllis Perrin Wilcox (2005) também salientam que, até 1964, os intérpretes de línguas de sinais atuavam de forma voluntária nos Estados Unidos, o que também colaborou para a popularização da Língua de Sinais Americana - ASL. A tradução e a interpretação eram feitas por filhos ouvintes de pais surdos, denominados CODAS. Em 1964, criou-se, no país, o primeiro registro de intérpretes para surdos, denominado Register of Interpreters for the Deaf-RID, o que serviu para impulsionar a formação e o treinamento dos profissionais da área de tradução para pessoas surdas. Surgem, além disso, ferramentas voltadas para a avaliação e certificação de intérpretes (WILCOX; WILCOX, 2005).

No contexto brasileiro, Quadros (2004) afirma que os primeiros registros da presença de tradutores e intérpretes de línguas de sinais ocorrem em instituições religiosas, na década de 1980. Antes disso, conforme Laguna (2015), aqueles que atuavam com surdos eram chamados de "repetidores de classe". Os repetidores eram, em geral, os próprios alunos do instituto (cursando semestres mais avançados), ou, em alguns casos, ex-alunos. Sua atividade consistia em repetir individualmente, para um aluno surdo, o conteúdo de forma oral e/ou escrita, auxiliá-lo nos estudos e no preparo das lições, e, ainda, assumir responsabilidades ligadas ao cuidado e ao disciplinamento daqueles alunos com os quais atuavam. Interessante observar que, além de voluntário, esse trabalho incorporava uma espécie de tutoria que, por sua vez, se sustentava numa perspectiva clínica da surdez. Esses profissionais recebiam, conforme a pesquisadora, uma formação empírica, ou seja, 
http://dx.doi.org/10.5902/1984686X40378

"educavam-se" na prática, no contato com os alunos surdos e com outros repetidores. Em um dos relatórios do Dr. Tobias Leite, diretor do INES de 1868 a 1896, encontram-se registros sobre a atuação e remuneração dos inspetores e repetidores, e o gestor mencionava a dificuldade em encontrar quem quisesse desempenhar essas tarefas devido à baixa remuneração atribuída ou ao caráter voluntário.

O trabalho cotidiano dos "repetidores de classe" era, tal como explica Laguna (2015), norteado pela experiência empírica, que definia, entre outras coisas, as formas de posicionar-se na presença do surdo - sentar-se à frente e próximo a este, mantendo-se à altura do olhar de seu interlocutor, mas permitindo que visualizasse o professor. A autora afirma não ter encontrado, entretanto, nenhum registro de documento prescritivo sobre essa atuação. O repetidor era frequentemente convocado a assumir atitude benevolente, ou aconselhado a ter paciência, para ser, assim, um modelo positivo para os surdos e lograr êxito na condução dos processos educativos.

Argumentamos que discursos benevolentes ainda ressoam em representações contemporâneas sobre a atuação dos tradutores e intérpretes de língua de sinais. Nesse sentido, a ideia de "modelo a ser seguido" está indicada, hoje, no Código de Ética dos Tradutores e Intérpretes de Língua de Sinais no Brasil ${ }^{3}$ - documento que faz parte do regimento interno do Departamento Nacional de Intérpretes da Federação Nacional de Educação e Integração dos Surdos - FENEIS. O referido código é apresentado, desde uma perspectiva histórica, pela relevância na conformação de certo lugar e de certa conduta desejável aos tradutores e intérpretes de língua de sinais. A base para a elaboração desse documento foi o código americano - Interpreting for Deaf People, de 1965 - traduzido por Ricardo Sander e adaptado pelos representantes dos estados brasileiros. No artigo $1^{\circ}$ do código se estabelece que "o intérprete deve ser uma pessoa de alto carácter moral, honesto, consciente, confidente e de equilíbrio emocional” (QUADROS, 2004, p. 31). Os aspectos apresentados colaboram para mostrar como os atuais profissionais foram sendo conformados a certo perfil historicamente engendrado, e os sentidos da profissão guardam alguma semelhança com a posição de repetidores, tutores, cuidadores, moralizadores de surdos.

Conforme Leite (2005), a primeira intérprete no país a traduzir em um evento oficial de ampla repercussão foi Denise Coutinho, durante a Assembleia Nacional Constituinte, no ano de 1987. Naquela ocasião, Ana Regina de Souza Campello e João Carlos Carreira Alves, ambos surdos, representavam as demandas das comunidades surdas, e Denise 
http://dx.doi.org/10.5902/1984686X40378

Coutinho atuou como intérprete em todas as sessões em que se discutiram direitos de pessoas com deficiência. Vale ressaltar que, naquele período, a atitude da jovem intérprete não era bem vista por alguns profissionais da área, que lançaram severas críticas ao fato de ter sido um trabalho voluntário, argumentando que essa atitude representava um retrocesso em relação às lutas por reconhecimento.

Nesse mesmo período, Ricardo Sander se torna conhecido por ser o primeiro intérprete a sinalizar o Hino Nacional Brasileiro em eventos oficiais da FENEIS. Interessante destacar que, como registra Rocha (2013), ele foi o primeiro intérprete sem vínculo familiar com surdos a atuar na área de modo sistemático. Ele teria se tornado tradutor e intérprete de língua de sinais em uma época em que não existiam cursos de formação específicos e em que a maioria dos intérpretes eram CODAS (filhos de pais surdos, conforme já mencionado).

No sul do Brasil, também no ano de 1986, ocorre o Seminário Internacional de Educação Religiosa para Surdos, na cidade de Porto Alegre/RS. Neste evento atuaram, como tradutores e intérpretes de Libras, Ricardo Sander e Ely Prieto, o que assegurou a comunicação entre surdos e ouvintes brasileiros e estrangeiros. Aliás, para muitos surdos brasileiros, esta foi a primeira oportunidade de acompanhar integralmente um evento em línguas de sinais. Vale ressaltar que a partir de 1988 foram sendo realizados, no Rio Grande do Sul, encontros sistemáticos, com o propósito de discutir a função do tradutor e intérprete de línguas de sinais e as especificidades da profissão. No estado, estabeleceu-se um regulamento que conceitua e orienta essa atuação, definindo quem poderá atuar como intérprete, assim como normas e critérios para isso.

O primeiro Encontro Nacional de Intérpretes de Língua de Sinais ocorreu em 1988, organizado pela FENEIS, e oportunizou o intercâmbio entre intérpretes do Brasil, bem como uma avaliação sobre aspectos ligados à interpretação. Em 1992, ocorreu o segundo Encontro Nacional de Intérpretes de Língua de Sinais, oportunidade em que se deu a votação e aprovação do já mencionado Código de Ética dos Tradutores e Intérpretes de Língua de Sinais no Brasil, documento que hoje integra o regimento interno do Departamento Nacional de Intérpretes da FENEIS. A base para a elaboração desse documento foi o código americano - Interpreting for Deaf People, de 1965 - traduzido por Ricardo Sander e adaptado pelos representantes dos estados brasileiros. Ainda, visando configurar o campo de ação possível e as atribuições dos tradutores e intérpretes de Libras, em 2004, o Ministério da Educação publicou, através do Programa Nacional de Apoio a 
http://dx.doi.org/10.5902/1984686X40378

educação de Surdos da Secretaria de Educação Especial SEESP e em parceria com a FENEIS, o código de ética anteriormente referido. Desde 2004 esse material vem sendo distribuído para todas as escolas, em suporte impresso, e encontra-se disponível em formato digital na página MEC.

A inclusão das pessoas surdas no sistema escolar regular se expandiu e a demanda pela acessibilidade linguística ${ }^{4}$ gerou, nos anos finais da década de 1990, a necessidade de implementação de cursos de formação de intérpretes pelo país, promovidos pela FENEIS. Um dos primeiros cursos ocorreu no Rio Grande do Sul, em 1997, promovido pela Universidade Federal do Rio Grande do Sul - UFRGS - em parceria com a FENEIS/RS. Vale lembrar que o Artigo 18 da Lei no 10.098/00 estabelece a obrigação de o poder público cuidar da formação de intérpretes de línguas de sinais. O Decreto dispõe, entre outros aspectos, sobre a formação necessária para os profissionais que atuam com a Língua Brasileira de Sinais. Neste decreto se estabelecem as exigências quanto à formação:

Art. 17. A formação do tradutor e intérprete de Libras - Língua Portuguesa deve efetivar-se por meio de curso superior de Tradução e Interpretação, com habilitação em Libras - Língua Portuguesa.

Art. 18. Nos próximos dez anos, a partir da publicação deste Decreto, a formação de tradutor e intérprete de Libras - Língua Portuguesa, em nível médio, deve ser realizada por meio de: I - cursos de educação profissional; II - cursos de extensão universitária; III - cursos de formação continuada promovidos por instituições de ensino superior e instituições credenciadas por secretarias de educação (Brasil, 2005).

Cinco anos depois é editada a Lei no 12.319, em 1ํ de setembro de 2010, lei que regulamenta o exercício da profissão de Tradutor e Intérprete da Língua Brasileira de Sinais. No Art. $2^{\circ}$, afirma-se que "o tradutor e intérprete terá competência para realizar interpretação das 2 (duas) línguas de maneira simultânea ou consecutiva e proficiência em tradução e interpretação da Libras e da Língua Portuguesa". O Art. $4^{\circ}$ da mesma lei estabelece que a formação profissional do tradutor e intérprete de Libras - Língua Portuguesa, em nível médio, deve ser realizada por meio de cursos de educação profissional reconhecidos pelo sistema que os credenciou; cursos de extensão universitária; e cursos de formação continuada promovidos por instituições de ensino superior e instituições credenciadas por Secretarias de Educação. Admite-se, também, formação oferecida por organizações da sociedade civil representativas da comunidade surda, desde que o certificado seja convalidado por uma das instituições de ensino superior credenciadas. 
http://dx.doi.org/10.5902/1984686X40378

\section{Avaliação, certificação e ingresso na carreira}

O Ministério da Educação lançou, em 2006, o Exame Nacional para Certificação de Proficiência no Ensino da Língua Brasileira de Sinais e para Certificação de Proficiência na Tradução e Interpretação da Libras/Língua Portuguesa - PROLIBRAS. Dada a relevância desse exame, realizamos uma busca no site da Comissão Permanente de Vestibular COPERVE, da Universidade Federal de Santa Catarina, bem como em relatórios técnicos das sete edições realizadas até o momento. Em relação aos critérios para participação no exame, observamos que, nos editais de 2006 a 2010, era necessário ser fluente em Libras e possuir escolaridade em nível médio ou superior. Havia, no período mencionado, dois tipos de certificação - uma em nível médio e outra em nível superior. Já nos editais de 2012/2013 e 2015, o pré-requisito era ser fluente em Libras e ter formação completa de nível médio. Conforme o Artigo $5^{\circ}$ da Lei $n$. 12.319/2010, o exame de proficiência em Tradução e Interpretação de Libras-Língua Portuguesa deve ser realizado por banca examinadora de amplo conhecimento dessa função, constituída por docentes surdos, linguistas e tradutores e intérpretes de Libras de instituições de educação superior.

Nos Editais examinados não constavam exigências explícitas quanto aos aspectos técnicos da tradução e interpretação. Entretanto, na avaliação do desempenho prático do candidato, considerava-se a adequação de sentido entre as duas línguas, a equivalência textual entre a Libras e o Português, a adequação gramatical em relação ao público-alvo, conforme critérios constantes dos relatórios. Tais exigências permitem pensar que, para realizar com êxito este exame, seria necessário ter atuado ou estar atuando como intérprete. A própria estrutura do PROLIBRAS requeria fluência, na medida em que envolvia tradução de um áudio para a língua brasileira de sinais e a interpretação oral de um vídeo sinalizado.

Sobre o perfil de candidatos, Claudio (2010) examinou quatro edições do exame 2006, 2007, 2008 e 2009 e observou que a maioria dos inscritos já tinha atuado (ou estava atuando) profissionalmente como instrutor ou professor de Libras, porém sem certificação. A pesquisadora realizou entrevistas com participantes desses exames e observou que, para muitos deles, o PROLIBRAS era o modo de obter titulação para fins profissionais, servindo para atestar a fluência em Libras, o que favorecia a busca por espaços de atuação remunerada.

Pode-se dizer que, diante da necessidade de habilitação específica para tradutores e intérpretes de línguas de sinais, após a publicação do Decreto 5.626/05, a resposta inicial 
http://dx.doi.org/10.5902/1984686X40378

foi implementar ações de certificação que permitissem profissionalizar o maior número de candidatos possível. Mesmo assim, ao nos depararmos com o total de candidatos inscritos e com o total de aprovados constantes nos relatórios do PROLIBRAS, encontramos um alto índice de reprovação. Observa-se, assim, que tais exames, longe de certificar compulsoriamente, pautaram-se por um "perfil" e também por critérios para aferir o domínio da língua de sinais, exigência básica para atuar na profissão.

Um dado interessante que observamos, analisando diretamente os relatórios de todas as edições do PROLIBRAS, diz respeito à certificação da modalidade de tradução e interpretação para pessoas surdas. Na primeira edição, em 2006, não houve possibilidade de ingresso de candidatos surdos. Entretanto, a partir da edição de 2007, o exame de proficiência passou a certificar pessoas surdas para a tradução e interpretação da língua brasileira de sinais. Contudo, os relatórios do PROLIBRAS de 2007 e 2008 mostram que não houve candidatos surdos aprovados. Já a edição de 2009 explicitava mais claramente como as avaliações de candidatos surdos deveria acontecer, de modo a atender especificidades linguísticas e as reivindicações da comunidade surda. Esta foi a "primeira edição a permitir que os candidatos surdos inscritos para Certificação em Tradução/Interpretação optassem pela realização da prova prática de forma escrita (e não oral)" 5 Os candidatos deveriam interpretar, em Libras, textos apresentados em língua portuguesa escrita e vice-versa.

Os relatórios do PROLIBRAS de 2010 e de 2015 estabelecem que a prova prática para os candidatos surdos, inscritos nas modalidades de tradução e interpretação, tem por objetivo cobrir determinadas "lacunas" ocorridas nos exames anteriores, reconhecendo que a restrição do processo à expressão oral impossibilitaria amplo acesso à certificação. Ao levantar os dados gerais sobre o número de tradutores e intérpretes certificados pelo PROLIBRAS em suas sete edições, concluímos que são raros os casos em que surdos foram certificados para atuar na área.

Vale ressaltar que existem sujeitos surdos que atuam como tradutores e intérpretes, em contextos específicos, dois dos quais descrevemos brevemente, a seguir. Em 2011, na cidade de Porto Alegre/RS, realizou-se um Festival Brasileiro de Cultura Surda, evento que contou com a participação de pessoas surdas de vários países. Nesta ocasião, presenciamos a tradução simultânea - feita por um surdo - da comunicação feita Língua Brasileira de Sinais para a língua internacional de sinais. Em determinados momentos, era utilizada a língua portuguesa oral e, então, a sinalização para LIBRAS era realizada por um 
http://dx.doi.org/10.5902/1984686X40378

tradutor e intérprete ouvinte e, a partir dela, a interpretação em língua internacional de sinais era feita por um surdo.

O segundo momento que desejamos destacar ocorreu em 2014, durante um curso de capacitação para Guia-Interpretação, realizado pela Associação Educacional para Pessoas com Múltiplas Deficiências Sensoriais - AHIMSA, na cidade de São Paulo, ocasião em que presenciamos traduções Libras para a língua de sinais tátil (modalidade destinada a pessoas surdocegas), feitas por um surdo. Neste processo tradutório, a mensagem transmitida em português oral era traduzida para Libras por um profissional ouvinte, e o intérprete surdo realizava a tradução tátil para uma pessoa com surdocegueira.

Os Concursos Públicos para tradutores e intérpretes de Libras constituem-se, neste estudo, importantes fontes de pesquisas sobre a profissão. No Estado do Rio Grande do Sul, Laguna (2012) examinou quatro editais de concursos públicos para ingresso de tradutores e intérpretes em instituições de ensino superior. No quesito formação, as exigências mínimas expressas nos editais eram: ter ensino médio completo, com curso de tradução/interpretação em Libras e/ou certificação através do PROLIBRAS; ou ter Ensino Médio com conhecimento e domínio na Língua Brasileira de Sinais. Vale destacar que a Lei no 12.319/2010, que regulamentava a profissão no período, não tinha como exigência de formação mínima a de nível superior para atuação em níveis mais elevados do ensino. No entanto, a Lei no 13.146/2015 passa a mencionar a necessidade de formação em nível superior para os tradutores e intérpretes de Libras que irão atuar nos cursos de Graduação e Pós-Graduação, mantendo, para os demais níveis, a exigência de formação em nível médio, desde que comprovada a proficiência na língua.

Sobre o PROLIBRAS, Laguna (2012) afirma que este modelo de avaliação e certificação tem sido problematizado, nos últimos anos, e se argumenta sobre a necessidade de investimentos públicos para assegurar sólidos processos de formação inicial e continuada para quem atua com tradução/interpretação em Libras. Ela destaca, ainda, que algumas propostas voltadas a responder rapidamente à demanda de formação de profissionais vêm sendo implementadas, com formatos de curta duração e/ou em nível de pós-graduação, mas muitos destes processos formativos têm negligenciado aspectos teóricos, técnicos e práticos que envolvem a tradução e a interpretação e vêm certificando profissionais pela frequência e participação no próprio curso, o que prejudicaria o desempenho posterior destes profissionais certificados. 
http://dx.doi.org/10.5902/1984686X40378

Nos dez anos previstos no Decreto nำ5.626/05 (2006 a 2015) para que o poder público viabilizasse a formação profissional adequada e suficiente para suprir as demandas, ampliaram-se as discussões e desenvolveram-se algumas iniciativas na direção de consolidar a profissão. Nesse sentido, Russo (2010) explica que, em 2008, teve início o curso de Bacharelado em Letras/Libras, promovido pela Universidade Federal de Santa Catarina - UFSC, ofertado na modalidade a distância para 15 polos do país. Esse foi o primeiro curso, em nível superior, ofertado no Brasil para a profissão, sendo iniciado em 2009 e ainda em oferta na atualidade. Em 2014, o curso foi ofertado na modalidade de ensino a distância. Foram iniciativas pioneiras e importantes, mas essa oferta não contemplou todos os estados brasileiros, e não assegurou, tampouco, a formação em nível superior para tradutores e intérpretes de Libras em número suficiente para atuar em universidades e faculdades do sul do país.

Atualmente são ofertados cursos em nível de graduação para tradutores e intérpretes de Libras em diferentes instituições brasileiras, a exemplo da Universidade Federal de Santa Catarina - UFSC, com graduação de Letras/Libras na modalidade presencial e a distância, esta última ofertada desde 2009 e, gradativamente, ampliada para outros estados por meio de parcerias com outras universidades federais. Além da referida instituição, outras oferecem graduação voltada à formação de tradutores e intérpretes de Libras, tais como a Universidade Federal do Rio de Janeiro - UFRJ, a Universidade Federal de Goiás - UFG, a Universidade Federal do Espírito Santo - UFES, a Universidade Federal de Roraima - UFRR, a Universidade Federal de São Carlos UFSCar, a Universidade Federal do Rio Grande do Sul - UFRGS, entre outras.

Trata-se, em geral, da formação de bacharéis, e vale indagar se ela contemplaria as demandas deste campo de atuação específico e habilitaria para uma atuação em todos os níveis de ensino. Pensamos que existem especificidades relativas à atuação de tradutores e intérpretes em diferentes níveis de ensino e, nesse sentido, uma formação pedagógica seria requerida, contemplando, além das disciplinas voltadas para o campo de tradução e interpretação, aspectos pedagógicos, didáticos e normativos do campo educacional.

Nos últimos anos, os tradutores e intérpretes de Libras vêm se organizando e buscando formas de regulamentação da profissão e de garantia de certos direitos trabalhistas para a categoria. Várias são as "bandeiras" de luta que envolvem a categoria, dentre as quais, destacam-se: a regulamentação do trabalho em duplas, em nível nacional, a garantia de horas remuneradas destinadas ao estudo e preparação para a tradução e, 
http://dx.doi.org/10.5902/1984686X40378

ainda, alguns segmentos profissionais reivindicam a adequação entre nível de formação requerido e funções desenvolvidas em instituições de Ensino Superior. Essa reivindicação, entretanto, está longe de ser consensual. Em relação a este último quesito, uma proposição constante, inicialmente, no Projeto de Lei no 325/2009, que previa habilitação em nível superior para tradutores e intérpretes que atuam em cursos de graduação e pós-graduação, foi vetada com o seguinte argumento: "ao impor a habilitação em curso superior específico e a criação de conselhos profissionais, os dispositivos impedem o exercício da atividade por profissionais de outras áreas, devidamente formados nos termos do art. $4^{\circ}$ da proposta, violando o art. 5\%, Inciso XIII da Constituição Federal".

Vale ressaltar, ainda, que a Lei no 13.146/2015, conhecida como Estatuto da Pessoa com Deficiência, também versa sobre a profissão em foco. No capítulo IV, que trata do Direito à Educação da pessoa surda, assim se registra:

$\S 2$ Na disponibilização de tradutores e intérpretes da Libras a que se refere o inciso XI do caput deste artigo, deve-se observar o seguinte:

I - os tradutores e intérpretes da Libras atuantes na educação básica devem, no mínimo, possuir ensino médio completo e certificado de proficiência na Libras;

II - os tradutores e intérpretes da Libras, quando direcionados à tarefa de interpretar nas salas de aula dos cursos de graduação e pós-graduação, devem possuir nível superior, com habilitação, prioritariamente, em Tradução e Interpretação em Libras. (Brasil, 2015).

A referida lei está em vigor desde sua publicação, tendo o governo um prazo de quatro anos para realizar as adequações concernentes à formação desses profissionais. Ao considerar necessária uma formação de nível superior para os tradutores e intérpretes de Libras que atuam neste mesmo nível de ensino, o poder público assume o compromisso de expandir as formas, as modalidades e os meios de formação adequada e de titulação desses profissionais.

Ao examinarmos concursos destinados a preencher vagas de tradutor e intérprete de Libras em diversas instituições federais, entre 2013 e 2016, realizamos uma busca no site da $\mathrm{PCl}$ concursos $^{6}$, utilizando a palavra-chave "Libras" e, do total de resultados, selecionamos 12 editais, utilizando como critérios a especificidade das vagas (cargo de tradutor e intérprete de língua de sinais), a instituição de oferta (universidades públicas) e o período (entre 2013 e 2016). No ano de 2013, selecionamos os editais das seguintes universidades: Universidade Federal do Pampa - UNIPAMPA/RS, Edital o 237/2013; Universidade Federal do Oeste do Pará - UFOPA, Edital no 001/2013; Universidade 
Federal de Uberlândia - UFU, Edital nำ 133/2013. Em 2014, selecionamos os editais a seguir: Fundação Universidade Federal do ACRE - FUFAC, Edital no 003/2014; Universidade Federal de Santa Maria - UFSM/RS, Edital no 007/2014; Universidade Federal de Lavras - MG, Edital no 083/2014. Em 2015, as instituições selecionadas foram: Universidade Federal do Rio Grande do SUL - UFRGS, Edital n 10/2015; Universidade Federal do Paraná - UFPR, Edital no 323/2015; Universidade Federal de São João Del Rei - UFSJ, Edital no 001/2015. Em 2016, selecionamos editais publicados nas instituições: Universidade Federal do Rio Grande - FURG/RS, Edital no 004/2016; Universidade Federal do Amazonas - UFAM, Edital n²2/2016; Universidade Federal de Santa Catarina - UFSC, Edital nº 015/2016.

Nessa análise, observamos que os cargos previstos são para pessoal de nível médio. Tais editais requerem, como determina a lei, o ensino médio completo e comprovação de aprovação no exame de proficiência - PROLIBRAS. Nessa busca, chamou nossa atenção o Edital da Universidade Federal de Santa Catarina, com vagas para tradutores e intérpretes de Libras em nível médio e superior ${ }^{7}$. As exigências de formação para vagas de nível médio são as mesmas dos demais editais, entretanto, a formação requerida para a seleção de profissionais tradutores e intérpretes de Libras em nível superior é a de graduação em Letras.

Embora ainda não haja um consenso na legislação brasileira, ampliaram-se nos últimos anos $(2017$ - 2018) as seleções para tradutores e intérpretes nas universidades com a exigência de qualificação em nível de graduação. Em alguns editais - para contratação em instituições privadas e em instituições públicas - a exigência de formação passou a ser titulação em curso de Letras/Libras, ou em curso de graduação com certificação de Proficiência na Tradução e Interpretação da Libras/Língua Portuguesa PROLIBRAS. Tal aspecto está previsto na Lei no 13.146/2015, (Artigo 28, § 2ํㅣㄱ. I), nos seguintes termos: "os tradutores e intérpretes da Libras, quando direcionados à tarefa de interpretar nas salas de aula dos cursos de graduação e pós-graduação, devem possuir nível superior, com habilitação, prioritariamente, em Tradução e Interpretação em Libras.” (Brasil, 2015).

No que tange à profissionalização, Russo (2010) dá relevo à atuação das associações criadas em vários estados do Brasil, cuja articulação culminou na criação da Federação Brasileira das Associações dos Profissionais Tradutores, Intérpretes e Guias intérpretes de Língua de Sinais - FEBRAPILS, em 2008. Esta federação tem fortalecido 
http://dx.doi.org/10.5902/1984686X40378

as lutas por direitos da profissão no território nacional. Vale ressaltar, por fim, que a FEBRAPILS é filiada a World Association of Sign Language Interpreters - WASLI, uma associação internacional que representa a profissão em várias partes do mundo.

As mudanças concernentes à formação requerida para atuar no âmbito do ensino superior vem sendo pauta de discussões em encontros da categoria e em eventos promovidos por associações de tradutores e intérpretes de Libras, uma vez que tais exigências legais estabelecem um filtro, impossibilitando a atuação de outros sujeitos com formações distintas. Nos movimentos da categoria profissional, é possível perceber que há uma preocupação dos tradutores e intérpretes que possuem graduação em diferentes áreas, inclusive entre aqueles que ocupam, nas universidades, cargos cuja exigência de formação (no ato de sua nomeação) era a de nível médio e que, por isso, pretendem permanecer nesse campo de atuação. Conforme já mencionamos, a exigência requerida em termos de formação encontra, como limite, o fato de que não há, no país, uma oferta de cursos de graduação nesta área que contemple a demanda nas universidades como um todo.

Interessadas em localizar documentos sobre a criação do cargo de tradutor e intérprete de Libras em nível E - correspondente ao nível superior - encontramos um relatório sobre o I Fórum dos Tradutores e Intérpretes de Língua de Sinais das Instituições Federais de Ensino, realizado pela Universidade Federal de Santa Catarina, entre os dias 12 e 14 de novembro de 2014. Nesse relatório, consta que estiveram presentes 115 representantes de 55 instituições federais de várias regiões do Brasil - e, inclusive, representantes da Federação Brasileira das Associações dos Profissionais Tradutores e Intérpretes e Guia-Intérpretes de Língua de Sinais (FEBRAPILS) e da Associação Catarinense de Tradutores e Intérpretes de Língua de Sinais (ACATILS).

O objetivo era discutir atuação, cargo e carreira dos tradutores e intérpretes de Libras em instituições de Ensino Superior. Entre os temas abordados, estava a criação de planos de carreira, a qualificação profissional, definições sobre carga horária, revezamento durante a atuação (trabalho em duplas), entre outros. O documento final desse encontro define algumas orientações para a atuação e regulamentação do trabalho dos tradutores e intérpretes de língua brasileira de sinais nas instituições de Ensino Superior. Os participantes do referido fórum encaminharam uma moção para a Conferência Nacional de Educação (CONAE, 2014), solicitando adequação do enquadramento funcional, no 
http://dx.doi.org/10.5902/1984686X40378

plano de carreira do tradutor e intérprete de Libras - de cargo de nível "D" para cargo de nível "E".

Manifestações específicas da categoria têm se ampliado - e podemos citar, por exemplo, que, na greve nacional dos servidores federais, ocorrida em 2015, tradutores e intérpretes de Libras apresentaram reivindicações específicas concernentes à profissionalização aos sindicatos locais e também à Federação dos Sindicatos dos Trabalhadores em Universidades Brasileiras - FASUBRA. Entre as reivindicações está a garantia de condições de trabalho nas instituições, tais como: a definição de locais de permanência para esses servidores no tempo em que permanecem na instituição, com condições para estudo e preparação do trabalho (leitura antecipada de textos indicados para aulas, estudo e revisão de termos específicos de distintos campos de saber, por exemplo); regulamentação do trabalho em dupla; criação de uma política institucional que contemple as especificidades da profissão, e ainda, previsão, em concursos futuros, de enquadramento profissional na categoria $E$, correspondente ao nível superior, conforme destacado anteriormente.

No entanto, no ano de 2019, entrou em vigor o Decreto no 10.185 , publicado no dia 20 de dezembro de 2019. Esse decreto extingue cargos efetivos e que vierem a vagar do quadro de pessoal da administração pública federal, e veta concursos públicos. Entre esses cargos, encontram-se o de Tradutor e Intérprete em nível superior, e o cargo de Tradutor e Intérprete da Linguagem de Sinais em nível médio, esse último vinha aparecendo com mais frequência nos editais de concursos destinados a suprir as vagas de tradutores e intérpretes de língua de sinais nas universidades. Dessa forma, embora tenhamos nos deparado com algumas movimentações da categoria de tradutores e intérpretes em prol de melhorias para a profissão, bem como da mudança de enquadramento funcional, conforme foi mencionado acima, não houve muitos avanços para o ingresso e carreira desses profissionais em nível federal.

\section{Considerações finais}

No foco do presente texto estão as lutas em torno da constituição da profissão de Tradutor e Intérprete de Libras. Afirmamos que qualquer discussão concernente à profissão deve tomar como ponto inicial as lutas políticas das comunidades surdas, 0 resguardo de seus direitos comunicacionais, sociais, culturais e políticos. Além disso, de uma perspectiva histórica, é possível vislumbrar o conjunto de reivindicações que vêm 
http://dx.doi.org/10.5902/1984686X40378

sendo conduzidas para expandir e consolidar a profissão. Emergem, nas últimas décadas, normativas que regulam e sustentam a atuação de tradutores e intérpretes de Libras, no Brasil, mas há, ainda, importantes pontos de tensão, relativas à formação, titulação, ingresso na profissão e enquadramento dos profissionais em planos de carreira de instituições. Os resultados do estudo mostram que a atuação desses profissionais esteve (e ainda persiste, em certa medida) marcada por um sentido de voluntariado, mas vai gradativamente adquirindo contornos distintos, regulamentada como uma profissão, o que colabora para o reconhecimento e fortalecimento de suas lutas.

Documentos como os códigos de ética estabelecem atitudes desejáveis e conformam o campo profissional, disciplinando, também, as condutas e os campos possíveis de ação. Contudo, não existe apenas um código de ética, e nem este é considerado basilar, como em outras profissões. Isso também aponta para uma variedade de sentidos e práticas em disputa na atualidade, que gradativamente tende à padronização, especialmente porque entra na ordem dos discursos e das políticas oficiais.

A profissão da qual nos ocupamos, no presente texto, tem contornos formais mais recentes, embora a presença de tradutores e intérpretes tenha contornos históricos e se registre, no país, desde os tempos imperiais, conforme argumentamos anteriormente. $\mathrm{O}$ fato de ser uma profissão regulamentada mais recentemente oferece muitas possibilidades, assim como muitos desafios para os sujeitos nela implicados. O cotidiano de tradutores e intérpretes é marcado por disputas - em torno de diferentes concepções do ato tradutório; em torno de direitos de sujeitos surdos que buscam assegurar condições condizentes de mediação linguística; em torno de exigências das instituições e em contextos de disputas sobre formas de enquadramento profissional nas categorias já existentes.

Ao que parece, a luta pela valorização é parte das exigências e pautas de profissionais, aliada ao reconhecimento de que a profissão requer conhecimentos e competências específicas, além de uma capacidade de viver na fronteira entre diferentes culturas e de atuar em condições cambiantes e em distintos espaços sociais e acadêmicos. É a partir das diversas experiências, realizadas em variados espaços e com sujeitos diferentes, bem como da dedicação ao estudo, à formação acadêmica e ao trabalho que os profissionais tradutores e intérpretes de Libras vão se constituindo, moldando-se aos preceitos da profissão e, ao mesmo tempo, lutando para expandir o alcance de suas ações. 
http://dx.doi.org/10.5902/1984686X40378

\section{Referências}

BRASIL. Lei no $\mathbf{1 0 . 4 3 6}$ de 24 de abril de 2002. Dispõe sobre a Língua Brasileira de Sinais - Libras e dá outras providências. Brasília, DF, 2002, 1p. Disponível em: http://www.planalto.gov.br/ccivil_03/leis/2002/L10436.htm. Acesso em: 18 ago. 2019.

BRASIL. Decreto no 5626 de 22 de dezembro de 2015. Regulamenta a Lei n 10.436, de 24 de abril de 2002, que dispõe sobre a Língua Brasileira de Sinais - Libras, e o art. 18 da Lei no 10.098, de 19 de dezembro de 2000. Brasília, DF, 2005, 7p. Disponível em: http://www.planalto.gov.br/ccivil_03/_ato2004-2006/2005/decreto/d5626.htm. Acesso em: 8 set. 2019.

BRASIL. Decreto no $\mathbf{1 0 . 1 8 5}$ de 20 de dezembro de 2019. Extingue cargos efetivos vagos e que vierem a vagar dos quadros de pessoal da administração pública federal e veda a abertura de concurso público e o provimento de vagas adicionais para os cargos que especifica. Disponível em: http://www.planalto.gov.br/ccivil_03/_ato2019-2022/2019. Acesso em: 20 jun. 2021.

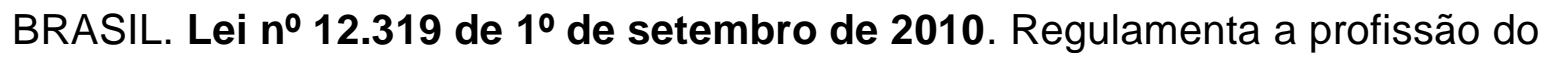
Tradutor/Intérprete de Língua de Sinais - LIBRAS. Brasília, DF, 2010, 1p. Disponível em: http://www.planalto.gov.br/ccivil_03/_Ato2007-2010/2010/Lei/L12319.htm. Acesso em: 09 set. 2019.

BRASIL. Lei no 13.146 de 06 de julho de 2015. Institui a Lei Brasileira de Inclusão da Pessoa com Deficiência (Estatuto da Pessoa com Deficiência). Brasília, DF, 2015, 34p. Disponível em: http://www.planalto.gov.br/ccivil_03/_Ato2015-

2018/2015/Lei/L13146.htm. Acesso em: 22 set. $201 \overline{9}$.

BRASIL. Câmara dos Deputados. Projeto de lei no 325 de 2009. Regulamenta a profissão de Tradutor e Intérprete da Língua Brasileira de Sinais - LIBRAS. Brasília, DF, 2004, 5p. Disponível em: https://www25.senado.leg.br/web/atividade/materias//materia/95215. Acesso em: 22 set. 2019.

BRASIL. Constituição da República Federativa do Brasil de 1988. Brasília, DF, 1988, 99p. Disponível em: http://www.planalto.gov.br/ccivil_03/Constituicao/Constituicao.htm. Acesso em: 10 set. 2019.

\section{CLAUDIO, Janaina Pereira. Proficiência em Língua Brasileira de Sinais -}

PROLIBRAS: representações sobre uso e ensino da Libras. 2010. 136 f. Dissertação (Mestrado em Educação) - Faculdade de Educação, Universidade Federal do Rio Grande do Sul - URGS, Porto Alegre/RS, 2010.

LAGUNA, Maria Cristina Viana. Moralidade, Idoneidade e Convivência: discursos sobre as práticas dos repetidores de classe do INES no período de 1855 a 1910 que incidem na atuação profissional dos tradutores-intérpretes de língua de sinais da atualidade. 2015. 155f. Dissertação (Mestrado em Educação) - Programa de PósGraduação em Educação. Faculdade de Educação. Universidade Federal do Rio Grande do Sul, Porto Alegre, 2015. 
LAGUNA, Maria Cristina Viana. Concursos Públicos para Intérpretes de Libras no Estado do Rio Grande do Sul. Anais eletrônicos do III Congresso Nacional de Pesquisas em Tradução e Interpretação de Libras e Língua Portuguesa.

Florianópolis, 2012. Disponível em:

http://www.congressotils.com.br/anais/anais/tils2012_politicasdetraducao_laguna.pdf. Acesso em: 22 de set. 2019.

LEITE, Emile Marques Costa. Comunidade Surda Brasileira: Sua Língua e Educação. In: LEITE, Emile Marques Costa (Org.). Os Papeis do intérprete de Libras na sala de aula inclusiva. Coleção Cultura e Diversidade. Petrópolis/RJ: Arara Azul, 2005, p. 2543.

MARTÍN-BARBERO, Jésus. Diversidade em convergência. Matrizes, V.8, № 2 jul./dez. 2014, p. 15-33.

QUADROS, Ronice Muller de. O tradutor e intérprete de língua brasileira de sinais e língua portuguesa. Secretaria de Educação Especial; Programa Nacional de Apoio à Educação de Surdos - Brasília: MEC; SEESP, 2004.

ROCHA, Valquíria Brito. A atuação do intérprete de Libras em escolas no Brasil: processos históricos. 2013. 23 f. Trabalho de Conclusão de Curso (TCC) - Faculdade de Educação, Universidade Estadual de Maringá, Maringá, 2013.

RUSSO, Ângela. Intérpretes de Língua de Sinais: Uma posição discursiva em construção. 2010. 133f. Dissertação (Mestrado em Educação) - Faculdade de Educação, Universidade Federal do Rio Grande do Sul, Porto Alegre, 2010.

TUXI, Patrícia. A Atuação do Intérprete Educacional no Ensino Fundamental. 2009. 123f. Dissertação (Mestrado) - Faculdade de Educação, Universidade de Brasília UNB. Brasília, 2009.

UNIVERSIDADE FEDERAL DE SANTA CATARINA. I Fórum dos Tradutores e Intérpretes de Língua de Sinais das Instituições Federais de Ensino. Florianópolis, SC, 2014, 12p. Documento disponível em:

http://forumtilspife.paginas.ufsc.br/files/2015/01/Relat\%C3\%B3rio_final_F\%C3\%B3rum.0 4_02_15.pdf. Acesso em: 6 ago. 2019.

UNIVERSIDADE FEDERAL DE SANTA CATARINA. Exame Nacional para Certificação de Proficiência no uso e no ensino da Libras e para Certificação de Proficiência na tradução e interpretação da Libras/Português/Libras. Disponível em: www.prolibras.ufsc.br/ edicoes-anteriores. Acesso em: ago. 2019.

WILCOX, Sherman; WILCOX Phyllis Perrin. A ASL e os Programas de Formação de Intérpretes. In: WILCOX, Sherman; WILCOX Phyllis Perrin (Org.). Aprender a ver. Coleção Cultura e Diversidade. Rio de Janeiro: Editora Arara Azul, 2005, p. 167- 173. 
http://dx.doi.org/10.5902/1984686X40378

\section{Notas}

${ }^{1}$ Esta lei "regulamenta o exercício da profissão de Tradutor e Intérprete da Língua Brasileira de Sinais LIBRAS" (Art. $1^{\circ}$ ); define que "o tradutor e intérprete terá competência para realizar interpretação das 2 (duas) línguas de maneira simultânea ou consecutiva e proficiência em tradução e interpretação da Libras e da Língua Portuguesa (Art. $2^{\circ}$ ). No Art $6^{\circ}$ definem-se as atribuições do profissional da seguinte forma: I - efetuar comunicação entre surdos e ouvintes, surdos e surdos, surdos e surdos-cegos, surdos-cegos e ouvintes, por meio da Libras para a língua oral e vice-versa; II - interpretar, em Língua Brasileira de Sinais - Língua Portuguesa, as atividades didático-pedagógicas e culturais desenvolvidas nas instituições de ensino nos níveis fundamental, médio e superior, de forma a viabilizar o acesso aos conteúdos curriculares; III - atuar nos processos seletivos para cursos na instituição de ensino e nos concursos públicos; IV - atuar no apoio à acessibilidade aos serviços e às atividades-fim das instituições de ensino e repartições públicas; e V - prestar seus serviços em depoimentos em juízo, em órgãos administrativos ou policiais. Disponível em http://www.planalto.gov.br/ccivil_03/_ato2007-2010/2010/lei/l12319.htm, acesso em 20 de favereiro de 2021.

${ }^{2}$ Trata-se da classificação oficial do Ministério do Trabalho (cuja primeira versão surgiu em 1982) na qual se reconhece, nomeia e codifica as profissões existentes e se descreve as características das ocupações do mercado de trabalho brasileiro. O cargo de "Tradutor-intérprete de Língua de Sinais" figura sob o n $^{\circ} 2614-25$, e tal nomenclatura tem, como sinônimas, outras expressões tais como: guia-intérprete; intérprete de Libras; intérprete educacional; tradutor de Libras, conforme informações constantes em http://www.ocupacoes.com.br/cbo-mte.

${ }^{3} \mathrm{O}$ referido código de ética pode ser lido, na íntegra, em QUADROS (2004, p. 31-40).

${ }^{4} \mathrm{O}$ conceito de acessibilidade, na redação dada pela Lei no 13.146 , de 2015 , prevê a "possibilidade e condição de alcance para utilização, com segurança e autonomia, de espaços, mobiliários, equipamentos urbanos, edificações, transportes, informação e comunicação, inclusive seus sistemas e tecnologias, bem como de outros serviços e instalações abertos ao público, de uso público ou privados de uso coletivo, tanto na zona urbana como na rural, por pessoa com deficiência ou com mobilidade reduzida". Disponível em http://www.planalto.gov.br/ccivil_03/_Ato2015-2018/2015/Lei/L13146.htm\#art112, acesso em 20 de fevereiro de 2021.

${ }^{5}$ Dos 59 candidatos surdos inscritos para essa Certificação, 52 optaram pela prova escrita (40 de nível médio e 12 de nível superior), os demais realizaram a prova de forma oral. As informações estão disponíveis no Relatório Tecnico PROLIBRAS 2009, em https://repositorio.ufsc.br/handle/123456789/134213.

6 Site destinado à publicação de editais de cursos em diferentes regiões do país. Disponível em: https://www.pciconcursos.com.br/.

7 Vale mencionar que, na UFSC, a primeira seleção para tradutores e intérpretes de Libras ocorreu no ano de 2009 e exigiu a formação em nível superior, conforme consta no edital $n^{\circ}$ 037/DDPP/2009. Disponível em: http://antiga.coperve.ufsc.br/concursos/ddpp/20092/edital/edital_complementar086.pdf. Já a segunda seleção teve como exigência formação em nível médio e em nível superior.

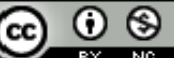

This work is licensed under a Creative Commons Attribution-NonCommercial 4.0 International (CC BY-NC 4.0) 